Pak. j. sci. ind. res. Ser. A: phys. sci. 2020 63A(2) 79-88

\title{
Studies of Liquid Fuel Formation from Plastic Waste by Catalytic Cracking Over Modified Natural Clay and Nickel Nanoparticles
}

\author{
Muhammad Salman Qureshi ${ }^{a *}$ Shazia Nisar ${ }^{\mathrm{a}}$, Raza Shah ${ }^{\mathrm{b}}$ and Hina Salman \\ ${ }^{a}$ Department of Chemistry, University of Karachi, Karachi-75270, Pakistan \\ ${ }^{b}$ HEJ Institute Chemistry, University of Karachi, Karachi-75270, Pakistan
}

(received April 9, 2018; revised September 16, 2019; accepted October 1, 2019)

\begin{abstract}
Plastics are the dominant part of waste. Recycling is a major challenge beside avoiding of plastic consumption. Development of economic catalysts is a crucial factor to provide cost effective recycling of plastics into fuels. The primary objective of this research is to use pure metallic nanoparticles and modified south Asian clay. These composite catalysts were investigated for the effectiveness and degradation of polymers into liquid fuels and compared their activity with commercially available catalytic material. A series of reactions were conducted in a $25 \mathrm{~cm}^{3}$ autoclave reactor under different conditions such as temperature, catalyst load, addition of active metals, and with nickel nanoparticles. The products distribution for the pyrolysis reactions were determined and compared with commercial kerosene, gasoline and diesel. Clay catalyst gave good liquid yield at $350{ }^{\circ} \mathrm{C}$ for low-density polyethylene and post-consumer poly-bags. $10 \%$ impregnation of nickel on natural clay gave maximum liquid yield $79.23 \%$ for LDPE, while for polybags it reached up to $76.01 \%$. The amount of liquid yield was found to increase to $12 \%$ and $18.6 \%$ for LDPE and poly-bags, respectively on the impregnation of nickel on clay compared to neat clay. It could be demonstrated as well that nickel nanoparticles and molybdenum impregnation on clay give a good yield on liquid fuel. The final products are in the range of gasoline, kerosene and diesel.
\end{abstract}

Keywords: plastic waste, pyrolysis, nickel nanoparticles, catalytic cracking, fuller earth clay

\section{Introduction}

Plastics are indispensable materials by choice due to their applications in every aspect of life. Use of plastic products in packaging, building materials, mobile phones, and medical devices are widespread. The USA alone produced 39.3 million tonnes (MT) of waste plastic in 2011 (Themelis and Mussche, 2014). At present, USA has the highest consumption of plastic equal to 39 MT. With the rapid growth of India produces 15000 tonnes/day, it is expected to rise to 24 MT by 2020 (Das and Tiwari, 2018; Singh and Biswajit, 2015). Plastic is a non-biodegradable material, subject to throw away culture and lack of an efficient waste management system it becomes socially concerned to dispose it safely. Pakistan lays in the third world under developing countries and classed among the worst country in waste management system. The growing awareness of environmental concerns and reducing landfill space have prompted research in alternative methods such as feedstock recycling by chemical means (Wan Abidah et al., 2018). This involves processes that convert plastic waste $(\mathrm{PW})$ into petroleum feedstock, preferably gasoline range fuels. Although a viable option, this method can

*Author for correspondence; E-mail: msq 98@hotmail.com be costly. Recycling of plastic provides an opportunity for its sustainable use by converting it into other useful products. There are several ways for the recycling of this bothersome material after its use, among them tertiary recycling gives us a chance to convert it into transportation fuel and another chemicals of high value. The most current issue is the high energy input required for some post-consumer plastic waste (PW) recycling due to its high temperature often higher $700{ }^{\circ} \mathrm{C}$. Due to this recycling industry is paying attention for developing catalysts. Catalysts not only reduce the time and temperature, but they also affect the nature of the final product. By using effective catalyst, these temperatures can be significantly reduced, thereby reducing cost. Nevertheless, the cost of catalysts can, in turn, affect the process economy considerably. Lowering the price even further will make Feedstock Recycling an even more attractive option. This option can be optimized by the following:

- Reuse of catalysts

- Use of active catalysts in small amounts

- Development of some economic catalyst from the structural modification of locally available source. 
In tertiary recycling, several attempts have been made to make this process economical. Some researchers studied the effects of acidity and basicity of silicaalumina $\mathrm{SiO}_{2}-\mathrm{Al}_{2} \mathrm{O}_{3}(45 \%)$ dotted with $\mathrm{NaOH}$ and $\gamma-$ $\mathrm{Al}_{2} \mathrm{O}_{3}$ on polystyrene degradation. They found that in case of acidic catalyst linear dimer could also isomerize into its cyclic derivatives which finally give benzene and methylindane after de-alkylation. On the other hand, presence of a base, ethylbenzene formation would be primary product due to selective formation of styrene that leads to coke formation (Marczewski et al., 2013). Another study revealed the catalytic activity of lead and cobalt on $\mathrm{BaTiO}_{3}$ based catalysts for the degradation of low-density polyethylene (LDPE). They observed that the addition of lead and cobalt increases the production of $\mathrm{C}_{13}-\mathrm{C}_{16}$ and $\mathrm{C}_{20}-\mathrm{C}_{30}$ compared to pure $\mathrm{BaTiO}_{3}$ (Ahmad et al., 2013). Zeolites are well known for the capability for polymer degradation, H-Y zeolite have also studied for degradation of polyethylene (PE), polypropylene (PP) and polystyrene (PS) in a batch reactor at $500{ }^{\circ} \mathrm{C}$. They found 42,44 and $71 \%$ liquid fraction for PE, PP, and PS degradation respectively (Lerici et al., 2015). Another zeolites ZSM-5 has been studied with boron impregnation. In fast catalytic pyrolysis (FCP) of LDPE, cellulose and their mixture in series of zeolites were loaded with boron in the range of $0.5-3.0$ wt. $\%$. Acidity and pore size of the ZSM-5 decreased due to boron deposition. It was found that $1 \%$ boron load favours monoaromatic hydrocarbons over undesirable polyaromatic hydrocarbons with selective production of $p$-xylene over $m$ - and $o$-xylenes in FCP. Plastic polymer also have synergetic effect with cellulose. Another study described that LDPE with cellulose improved the product distribution towards the valuable materials, they showed $20.0 \%$ increment in the production of the mono-aromatic products (Zhou et al., 2014). Synergetic effects of plastics with stem wood were studied and found in co-pyrolysis reaction that reduce carbonyl containing oxygenate and aldehyde (Johansson et al., 2018; Lin et al., 2018).

Over the last century, clays were widely used in the petroleum industry as catalysts or as catalyst supports (Emam, 2013). The primary use of clay in petroleum industries is in hydrocracking, catalytic cracking, reforming, hydrogenation, alkylation, isomerization, etc. They also modified Kaolin clay for plastic degradation for better results for the desired yield (Singh and Biswajit, 2015).
Nickel is widely used in cracking industry recently (Vichaphund et al., 2017) study the effect of nickel on ZSM-5 for the formation of an aromatic compound in pyrolysis of rubber polymer. They found that the addition of nickel on ZSM-5 increase the normalized peak area of the aromatic compound from 20.67 to $66.27 \%$, when polymer and catalyst ratio set as 1:1. Another group determined the role of nickel on ZSM-5, y-zeolite, $\beta$ zeolite and natural zeolite (clinoptilolite) for the degradation of polyethylene terephthalate (PET) on the tubular reactor. And reported that addition of nickel loaded zeolite increases the cracking yield and more gas content was found (Al-Asadi and Miskolizi, 2018, nanoparticles (NPs) have fascinating properties like mechanical, chemical, magnetic, optical, electrical etc. it becomes a subject of interest for researchers. Large surface to volume ratio is the main reason for getting popular in research. Small particles are more susceptible to collision and effect more profoundly on reaction system (Wagner and Schmidi, 1995; Ozaki, 1989; Moore, 1985). In our previous work, nickel was used as a supporting material (Ali and Qureshi, 2013).

The first goal of this present study is to investigate the catalytic decomposition of polyethylene (PE) and polybags (PB) using modified clay catalyst. South Asian soil is rich in sedimentary clay in that, natural clay (NC) from the city of Multan classified as bentonite and montmorillonite is most famous for its benevolent use in the daily life. In present study, we used this natural clay for the catalytic degradation to provide an economic value catalyst source. In this work, we evaluated the degradation activity of this modified clay with nickel and molybdenum to obtain maximum liquid fuel from LDPE and poly-bags. The second goal of this study is to investigate the catalytic performance of nickel nanoparticles. Nickel has proven catalytic activity for polymer degradation. Several researchers have reported the utility of nickel in cracking industry (Syamsiro et al., 2014; Ali et al., 2006).

\section{Material and Methods}

The clay was obtained from Multan district province of Punjab polyethylene shopper bags were collected from local dumping side and LDPE from Saudi Basic Industries Corporation, Riyadh, Saudi Arabia (SABIC). Nickel and molybdenum salts were taken from Sigma Aldrich. 
Natural clay was use after activation and modified by the addition of nickel and molybdenum using the incipient wetness method as in previous work (Ali et al., 2011). Three concentrations 5, $10 \& 15 \%$ of nickel added on natural clay (NC) named as NC-5-Ni, $\mathrm{NC}-10-\mathrm{Ni}$, and NC-15-Ni, respectively. Similarly, three levels $5,10 \& 15 \%$ of molybdenum added on natural clay (NC) named as NC-5-Mo, NC-10-Mo, and NC15-Mo, respectively. Moreover, synthesized nickel nanoparticles were also studied for their catalytic property in pyrolysis reaction. To compare developed products three other commercially available catalysts Mordenite, USY Zeolite \& AKZO KC-2710 were also evaluated. Pure silica was used for temperature optimization which has no known catalytic activity. Details of catalyst is in Table 1 .

Synthesis of clay-based catalyst. A method described in literature was used for the synthesis of catalyst (Ali et al., 2009). A fine homogeneous powder of natural clay (NC) was soaked in 10\% hydrofluoric acid in 1:1 ratio for base activation for $2 \mathrm{~h}$ at room temperature and then heated at $120^{\circ} \mathrm{C}$ till dryness, then calcined up to $550^{\circ} \mathrm{C}$ for six hours and stored in polybags (Emam, 2013). Metal salt was added by incipient wetness method. A saturated aqueous solution containing nickel ( $\mathrm{Ni}$ ) and molybdenum (Mo) salts were prepared and then allowed for capillary or dry ion-exchange at $25^{\circ} \mathrm{C}$ separately. Incipient wetness is commonly used for preparation of dry heterogeneous catalysts in which solution of metals of interest allowed to enter into inner pore of catalyst for their catalytic role. The metal impregnated clay was again heated up to $120^{\circ} \mathrm{C}$ for $1 \mathrm{~h}$ and finally calcined

Table 1. Catalysts description and source

\begin{tabular}{ll}
\hline \hline Catalyst name & Catalyst source \\
\hline Natural clay (NC) & Local collection \\
NC- $5^{*}-\mathrm{Ni}$ & Lab modified \\
$\mathrm{NC}-10^{*}-\mathrm{Ni}$ & Lab modified \\
$\mathrm{NC}-15^{*}-\mathrm{Ni}$ & Lab modified \\
$\mathrm{NC}-5^{*}-\mathrm{Mo}$ & Lab modified \\
$\mathrm{NC}-10^{*}-\mathrm{Mo}$ & Lab modified \\
$\mathrm{NC}-15^{*}-\mathrm{Mo}$ & Lab modified \\
Nickel nanoparticles & Lab synthesized \\
Silica $\left(\mathrm{SiO}_{2}\right)$ & Sigma-Aldrich \\
Mordenite & Local supplier \\
USY Zeolite & Local supplier \\
AKZO KC-2710 & Local supplier \\
\hline \hline
\end{tabular}

*percentage of metals (Ni/Mo). at $550{ }^{\circ} \mathrm{C}$ for $6 \mathrm{~h}$. Reduction of metals deposited at inner pore of catalyst was achieved by using molecular hydrogen as gas provided by gas cylinder.

Synthesis of nickel nanoparticles (NNPs) for catalytic purposes. Nickel nanoparticles (NNPs) were synthesized in a non-aqueous medium using ethanolic nickel chloride solution by following the procedure in literature (Mandeep et al., 2011). Hydrazine monohydrate was used as a reducing agent that released nitrogen and provided an inert atmosphere. Polyvinyl pyrrolidone (PVP) was used as a capping agent to reduce the surface energy of particles. $60 \mathrm{~mL}$ of $3.3 \mathrm{mM}$ ethanolic solution of nickel chloride hexahydrate $\mathrm{NiCl}_{2} .6 \mathrm{H}_{2} \mathrm{O}$ was taken in a round bottom flask, and $0.025 \mathrm{~g}$ of polyvinyl pyrrolidone (PVP) as capping agent added to it. $1.7 \mathrm{~mL}$ of $1 \mathrm{M} \mathrm{NaOH}$ was then added with constant stirring followed by $8 \mathrm{~mL}$ of hydrazine monohydrate. Finally, the solution heated to $60{ }^{\circ} \mathrm{C}$ with constant shaking. Nanoparticles (NPs) appeared within about $5 \mathrm{~min}$. After cooling at room temperature, acetone added in excess. The mixture centrifuged for separation of nanoparticles (NPs). Finally, particles washed with chloroformmethanol (1:1) solution.

Elemental analysis. Clay sample was digested in Mars microwave digestion oven (CEM corp., Matthews, NC) using EPA 3052. (EPA, 1996) (Wilson et al., 2006). For $250 \mathrm{mg}$ of sample, $4 \mathrm{~mL}$ concentrated hydrofluoric acid, $9 \mathrm{~mL} \mathrm{HNO}_{3}, 3 \mathrm{~mL} \mathrm{HCl}$ and $10 \mathrm{~mL} \mathrm{2.5 \%} \mathrm{boric}$ acid were added. The vessels were sealed for heating up to $160{ }^{\circ} \mathrm{C}$ for $10 \mathrm{~min}$ and then made up to $50 \mathrm{~mL}$ with water after cooling. ICP-OES (Model 7500DV) of Perkin Elmer used for analysis. Lead $(\mathrm{Pb})$, cadmium (Cd), calcium $(\mathrm{Ca})$, cobalt $(\mathrm{Co})$, chromium $(\mathrm{Cr})$, copper $(\mathrm{Cu})$, iron $(\mathrm{Fe})$, magnesium $(\mathrm{Mg})$, manganese $(\mathrm{Mn})$, lithium ( $(\mathrm{Li})$, molybdenum (Mo), nickel (Ni), antimony $(\mathrm{Sb})$, strontium $(\mathrm{Sr})$ and titanium $(\mathrm{Ti})$ were analyzed.

Batch reactor experiments. A $25 \mathrm{~cm}^{3}$ stainless steel tubular batch reactor from Parr instruments with a builtin stirrer was used for pyrolysis reactions of waste plastic. Three temperatures, 350,400 and $450{ }^{\circ} \mathrm{C}$ were used in the presence of nitrogen gas with constant stirring. Similarly, 5, 8 and $12 \mathrm{wt} \%$ catalyst load were applied on a total charge basis. The reactions were followed by quantitative determination of masses regarding gas, oil, pre-asphaltene, and insoluble material. The fraction soluble in hexane was assumed as oil fraction; the toluene soluble fraction was considered as pre-asphaltenes, and THF insoluble fraction as inorganic 
material (IM). Percent gas content was calculated by the difference in mass balance equation as. Gas $\%=$ $100 \%$ - (liquid $\%$ + solid\%). Percent conversion (PC) defined as; $\mathrm{PC}=100$ - (IM\%). The boiling range distribution was determined by GC-FID using a $30 \mathrm{~m} \mathrm{DB}$ $5 \mathrm{~ms}$ column. The temperature range was maintained at $5{ }^{\circ} \mathrm{C} / \mathrm{min}$ to final $240{ }^{\circ} \mathrm{C}$ and held for $35 \mathrm{~min}$ by using nitrogen as a carrier gas.

\section{Results and Discussion}

The primary objective of this study is to focus on a lowcost approach for the recycling of enormously generated plastic waste via tertiary recycling which is the main hurdle of sustainable development of society via tertiary recycling that provides the liquid product in transportation fuel range. In this study, we also cover the catalytic property of nickel nanoparticle. Catalyst support and local sourced based catalyst or catalyst support will provide the uninterrupted supply at a low-cost for the process.

Thermal pyrolysis of plastic with $\mathrm{SiO}_{2}$. Thermal degradation of LDPE and poly-bags (PB) was determined in the optimization experiment. Polymers started to degrade at their threshold temperature that depended upon their internal structure. The rate of degradation depended on their binding structure, and the products evolved in each preceding step. Mass balance of LDPE and post-consumer plastics were determined for the reaction variables of temperature, catalyst load, nickel and molybdenum content by gravimetric methods. Pure silica $\left(\mathrm{SiO}_{2}\right)$ used for the determination of temperature effect that has no catalytic activity. Three temperature $350,400 \& 450{ }^{\circ} \mathrm{C}$ were selected. A group of researcher observed the inverse relation of liquid yield with temperature (Su et al., 2010). Degradation started from the surface of polymers with the elimination of lighter gas content, at a higher temperature lower molecular weight hydrocarbons escaped from the surface more rapidly resulting higher coke content (Su, 2010). LDPE gave good yield of liquid at $350{ }^{\circ} \mathrm{C}(60.66 \%)$ compared to $400{ }^{\circ} \mathrm{C}(53.63 \%) \& 450{ }^{\circ} \mathrm{C}(13.20 \%)$, which is in good relation with literature, whereas, for poly-bags, the difference in liquid yield at $350{ }^{\circ} \mathrm{C}(55.91 \%) \& 400$ ${ }^{\circ} \mathrm{C}(57.22 \%)$ was not significant ( $1.31 \%$ only). The liquid yield at $450{ }^{\circ} \mathrm{C}$ found just $(13.2 \%) .350{ }^{\circ} \mathrm{C}$ was selected for all the following experiments. Other works have also reported the same pattern (Ahmad et al., 2013; Yu-Tung et al., 2012; Lin et al., 2007; Salvador and Cardona, 2000; Willams and Azzal, 1995).
Effect of natural clay (NC) as catalyst on pyrolysis of LDPE and poly-bags. The optimum condition for natural clay was also determined and found that LDPE at $350{ }^{\circ} \mathrm{C}$ with $5 \%$ natural clay (NC) catalyst load gave a good liquid yield (69.72\%) compared to thermal cracking $(60.66 \%)$ that proved the utility of natural clay as catalyst over the thermal process. On the other hand, at $350{ }^{\circ} \mathrm{C}$ with $8 \%$ natural clay (NC) catalyst load was found useful for used poly-bags that yield (61.91\%) compared to thermal cracking (55.91\%). $8 \% \mathrm{NC}$ also produced (30.1\%) gas and (2.76\%) IM. Natural clay gave liquid yield (56.82\%) and (54.53\%) for LDPE and poly-bags respectively at $12 \%$ natural clay load. Other than liquid quantity, product distribution is another essential tool for catalyst performance. For the determination of product distribution, liquid products were analyzed in $\mathrm{GC}$ with a flame ionization detector (Shimadzu Model GC-2014 AFSC). GC profile was divided into three zones on the basis of elution time that depends upon boiling point namely, 0 to $20 \mathrm{~min}$, 20 to $40 \mathrm{~min}$ and 40 to $60 \mathrm{~min}$ for the comparison with commercial gasoline, kerosene and diesel.

Effect of nickel nanoparticles load on pyrolysis. Catalytic behaviour of nickel nanoparticles (NNPs) was also evaluated for polymer degradation. A non-aqueous synthesis was performed using hydrazine for the formation of nickel nanoparticles. Hydrazine itself provides the inert atmosphere for the reaction by releasing nitrogen. Synthesized nickel nanoparticles (NNPs) were characterized by dynamic light scanning (DLS) and scanning electron microscope (SEM). Figure 1 represents particle size distribution on 10 times diluted sample of $5 \% \mathrm{wt} / \mathrm{vol}$ solution, the average size of Nanoparticles (NPs) was found to be $628.2 \mathrm{~nm}$.

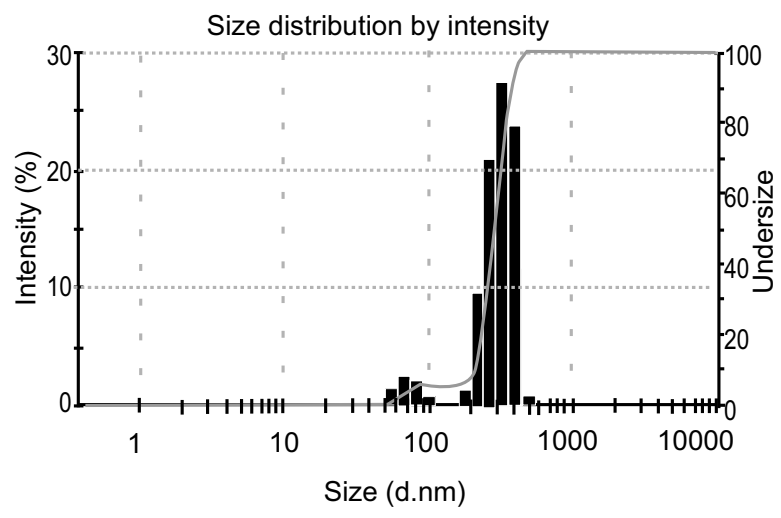

Fig. 1. Nickel nanoparticles size distribution. 
Particle size of nickel nanoparticles (NNPs) was determined on Malvern zeta sizer with non-invasive backscatter, optics for 90 scattering using S cell at 25 ${ }^{\circ}$ C. 5\% wt./vol. aqueous solution of nickel nanoparticles prepared and diluted further 10 times for analysis.

Surface topography and area of the catalyst are significant factors in its performance (Ali et al., 2011). Scanning electron microscope (SEM) images in Fig. $2 \mathrm{a}$ and $\mathrm{b}$ show regular spherical or polydispersed structure with the uniform size of nickel nanoparticles. Researchers showed that topography of ingredients salts such as crystals and cubic have no effect on the shape of final metallic particles (Kahani and Molaei, 2013). Nonaqueous synthesis provides the fine granules for the catalytic reaction. SEM image showed the uniform particles size.

Nanotechnology is extending their application into the previously unapproached field. Nickel is widely used in petroleum and plastic waste recycling industry. Synthesized nickel nanoparticles (NNPs) were evaluated for their catalytic activity in polymer degradation. Adsorption of molecules on nanoparticles increases due to the increase in surface area of nickel as compared to bulk. The effect of nickel nanoparticles with LDPE and poly-bags were investigated and given in Table 2 . Nickel nanoparticles (NNPs) was mixed in 5, 8 and $12 \%$ of polymer weight. Nickel nanoparticles (NNPs) at 5\% load on LDPE gave $(70.66 \%)$ of liquid product whereas, $8 \%$ of nickel nanoparticles (NNPs) gave (74.63\%). Further addition of nickel nanoparticles (NNPs) did not give a significant amount of liquid. Addition of $12 \%$ nickel nanoparticles (NNPs) on LDPE gave just (0.57\%) higher yield from $(74.63 \%)$ to $(75.2 \%)$ of liquid products. Similarly, for the poly-bags difference in liquid yield at $8 \%$ and at $12 \%$ load found just $(0.06 \%)$.
Inorganic material and gas also determined and found that $8 \%$ and $12 \%$ load of nickel nanoparticles (NNPs) gave gas and IM\% in a significant amount. For LDPE $12 \%$ nickel nanoparticles (NNPs) load gave almost double the inorganic material (IM\%) about (3.56\%) compare with $8 \%$ load (1.73\%). Similarly, for polybags when nickel nanoparticles (NNPs) load increases from $8 \%$ to $12 \%$, IM $\%$ become double from $(2.61 \%)$ to $(4.67 \%)$, respectively. Generally, the surface area of the catalyst has a direct relation with activity; a high

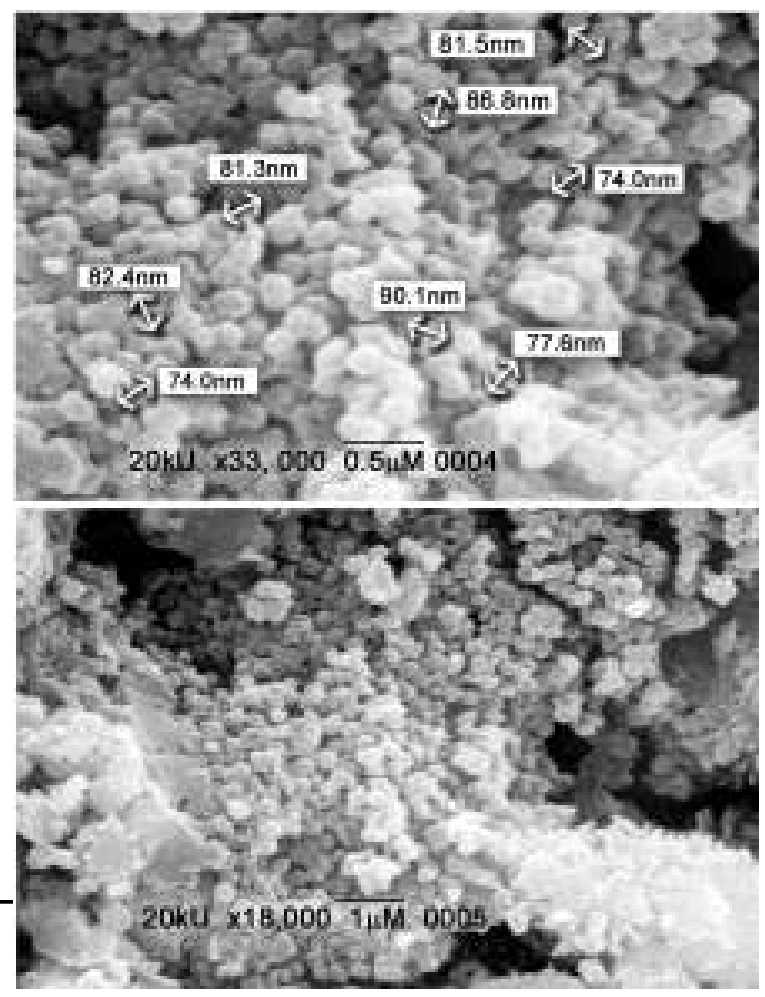

Fig. 2 a and b. SEM image of nickel nanoparticles.

Table 2. Effect of nickel nanoparticles (NNPs) on pyrolysis of LDPE \& poly-bags at $350{ }^{\circ} \mathrm{C}$

\begin{tabular}{|c|c|c|c|c|c|c|c|c|c|c|}
\hline \multirow[b]{2}{*}{ Polymers } & \multirow[b]{2}{*}{ Catalyst (\%) } & \multirow[b]{2}{*}{$\operatorname{Hex} .(\%)^{a}$} & \multirow[b]{2}{*}{ Tol. $(\%)^{b}$} & \multirow[b]{2}{*}{$\mathrm{THF}(\%)^{\mathrm{c}}$} & \multirow[b]{2}{*}{$\operatorname{Gas}(\%)^{\mathrm{d}}$} & \multirow[b]{2}{*}{$\operatorname{IM}(\%)^{\mathrm{e}}$} & \multicolumn{4}{|c|}{ Area $\%$ of retention time (min.) } \\
\hline & & & & & & & Conversion & Start 0-20 & $20-40$ & $40-60$ \\
\hline \multirow[t]{3}{*}{ LDPE } & 5 & 70.66 & 3.01 & 1.88 & 21.69 & 2.76 & 97.24 & 29.05 & 30.28 & 40.67 \\
\hline & 8 & 74.63 & 1.25 & 0.97 & 21.42 & 1.73 & 98.27 & 22.99 & 32.34 & 44.67 \\
\hline & 12 & 75.20 & 1.44 & 0.73 & 19.07 & 3.56 & 96.44 & 19.36 & 34.67 & 45.97 \\
\hline \multirow[t]{3}{*}{ Poly bags } & 5 & 61.91 & 0.76 & 1.20 & 33.19 & 2.94 & 97.06 & 30.61 & 27.69 & 41.70 \\
\hline & 8 & 65.52 & 1.99 & 1.69 & 28.19 & 2.61 & 97.39 & 29.23 & 22.90 & 47.87 \\
\hline & 12 & 65.58 & 3.01 & 0.84 & 25.90 & 4.67 & 95.33 & 26.72 & 36.57 & 36.71 \\
\hline
\end{tabular}

${ }^{\mathrm{a}} \mathrm{wt} .=$ percentage of hexane soluble material; ${ }^{\mathrm{b}} \mathrm{wt} .=$ percentage of toluene soluble material; ${ }^{\mathrm{c}} \mathrm{wt} .=$ percentage of THF soluble material; ${ }^{\mathrm{d}}=$ gas percentage wt. $/ \mathrm{wt}^{\mathrm{e}}{ }^{\mathrm{e}}=$ inorganic material percentage wt./wt. 
surface area could change the nature of pyrolytic reaction and effects on results even at lower concentration (HungTa et al., 2010; Marcilla et al., 2003). Nickel nanoparticles (NNPs) not only impact on solid fraction but also promotes the product to the higher boiling point (BP) compounds as shown in Table 2. GC analysis shows that the product ranged from gasoline to diesel range.

High IM\% content due to the formation of coke or residue that blocks the active side of catalyst and make it unavailable for other molecules. Aromatization and dehydrogenation on catalyst surface could be the cause of coke or residue formation (Abbas-Abadi et al., 2014). Some literature suggests the inverse relation between the formation of gas with coke or residue due to secondary reaction occurs at the surface of catalyst that results in coke formation (Abbas-Abadi et al., 2012).

Effect of nickel on the catalytic activity on natural clay (NC) for pyrolysis of LDPE and poly-bags. Natural clay used in this work was found to contains a large amount of iron (67000 ppm), calcium (13000 $\mathrm{ppm})$, and titanium (7800 ppm). The analysis further showed that this clay did not contain nickel or molybdenum which are widely used in cracking process (Abbas-Abadi et al., 2013). Impregnation of nickel and molybdenum on clay was performed in the presen study and the effect on the product was measured.

Natural clay (NC) was impregnated with 5, 10, 15\% of nickel for the enhancement of catalytic property. Table 3 shows the effect of nickel impregnation on polymer degradation. Effect of nickel addition was more pronounced on poly-bags than on LDPE. For LDPE, $10 \%$ addition of nickel gave $(79.23 \%)$ liquid products, about $9.5 \%$ increase compared with natural clay, whereas poly-bags, gave (76.01\%) hexane soluble $14 \%$ more liquid than with natural clay. Nickel impregnation also affected product distribution and provided a higher amount of kerosene to diesel products.

Effect of molybdenum on catalytic activity of natural clay (NC) for pyrolysis of LDPE \& poly-bags. Molybdenum is another well-known metal used in the fluid cracking catalyst ( $\mathrm{Su}, 2010)$. Natural clay (NC) was impregnated with molybdenum with 5,10 and $15 \%$ its effects were evaluated. Table 4 shows that the addition

Table 3. Effect of nickel on natural clay on product distribution for pyrolysis of LDPE and poly-bags at $350{ }^{\circ} \mathrm{C}$

\begin{tabular}{|c|c|c|c|c|c|c|c|c|c|c|}
\hline \multirow[b]{2}{*}{ Polymers } & \multirow[b]{2}{*}{ Catalyst $(\%)$} & \multirow[b]{2}{*}{$\operatorname{Hex} .(\%)^{\mathrm{a}}$} & \multirow[b]{2}{*}{ Tol. $(\%)^{b}$} & \multirow[b]{2}{*}{$\operatorname{THF}(\%)^{\mathrm{c}}$} & \multirow[b]{2}{*}{$\operatorname{Gas}(\%)^{\mathrm{d}}$} & \multirow[b]{2}{*}{$\operatorname{IM}(\%)^{\mathrm{e}}$} & \multicolumn{4}{|c|}{ Normalized area of retention time (min.) } \\
\hline & & & & & & & Conversion & Start $0-20$ & $20-40$ & $40-60$ \\
\hline \multirow[t]{3}{*}{ LDPE } & $\mathrm{NC}-5-\mathrm{Ni}$ & 72.66 & 2.63 & 2.41 & 19.27 & 3.03 & 96.97 & 36.56 & 52.11 & 11.33 \\
\hline & $\mathrm{NC}-10-\mathrm{Ni}$ & 79.23 & 1.18 & 2.45 & 13.19 & 3.95 & 96.05 & 40.82 & 41.23 & 17.95 \\
\hline & $\mathrm{NC}-15-\mathrm{Ni}$ & 75.38 & 1.00 & 3.66 & 16.43 & 3.53 & 96.47 & 39.55 & 47.97 & 12.48 \\
\hline \multirow[t]{3}{*}{ Poly bags } & $\mathrm{NC}-5-\mathrm{Ni}$ & 68.07 & 1.11 & 2.01 & 26.09 & 2.72 & 97.28 & 42.66 & 39.42 & 17.92 \\
\hline & $\mathrm{NC}-10-\mathrm{Ni}$ & 76.01 & 1.37 & 2.44 & 17.12 & 3.06 & 96.94 & 24.36 & 51.29 & 24.35 \\
\hline & $\mathrm{NC}-15-\mathrm{Ni}$ & 71.11 & 1.29 & 1.56 & 22.02 & 4.02 & 96.98 & 36.51 & 42.87 & 20.62 \\
\hline
\end{tabular}

${ }^{\mathrm{a}}$ wt. $=$ percentage of hexane soluble material; ${ }^{\mathrm{b}} \mathrm{wt} .=$ percentage of toluene soluble material; ${ }^{\mathrm{c}} \mathrm{wt} .=$ percentage of THF soluble material; ${ }^{\mathrm{d}}=$ gas percentage wt. $/$ wt.; ${ }^{\mathrm{e}}=$ inorganic material percentage wt./wt.

Table 4. Effect of molybdenum on natural clay for pyrolysis of LDPE and poly-bags at $350{ }^{\circ} \mathrm{C}$

\begin{tabular}{|c|c|c|c|c|c|c|c|c|c|c|}
\hline \multirow[b]{2}{*}{ Polymers } & \multirow[b]{2}{*}{ Catalyst (\%) } & \multirow[b]{2}{*}{ Hex. $(\%)^{\mathrm{a}}$} & \multirow[b]{2}{*}{ Tol. $(\%)^{b}$} & \multirow[b]{2}{*}{$\operatorname{THF}(\%)^{\mathrm{c}}$} & \multirow[b]{2}{*}{$\operatorname{Gas}(\%)^{\mathrm{d}}$} & \multirow[b]{2}{*}{$\operatorname{IM}(\%)^{\mathrm{e}}$} & \multicolumn{4}{|c|}{ Area $\%$ of retention time (min.) } \\
\hline & & & & & & & Conversion & Start 0-20 & $20-40$ & $40-60$ \\
\hline \multirow[t]{3}{*}{ LDPE } & NC-5-Mo & 70.81 & 1.07 & 1.76 & 24.07 & 2.29 & 97.71 & 23.84 & 59.56 & 16.60 \\
\hline & NC-10-Mo & 69.36 & 1.06 & 0.77 & 26.63 & 2.18 & 97.82 & 24.44 & 62.12 & 13.44 \\
\hline & NC-15-Mo & 71.56 & 1.21 & 1.69 & 24.03 & 1.51 & 98.49 & 18.68 & 61.92 & 19.40 \\
\hline \multirow[t]{3}{*}{ Poly bags } & NC-5-Mo & 62.14 & 1.77 & 1.27 & 30.82 & 4.00 & 96.00 & 26.93 & 54.96 & 18.11 \\
\hline & NC-10-Mo & 61.97 & 1.23 & 1.11 & 33.15 & 2.54 & 97.46 & 28.67 & 58.62 & 12.71 \\
\hline & NC-15-Mo & 62.33 & 2.06 & 1.02 & 31.71 & 2.88 & 97.12 & 21.69 & 59.61 & 18.70 \\
\hline
\end{tabular}

${ }^{\mathrm{a}} \mathrm{wt} .=$ percentage of hexane soluble material; ${ }^{\mathrm{b}} \mathrm{wt} .=$ percentage of toluene soluble material; ${ }^{\mathrm{c}} \mathrm{wt} .=$ percentage of THF soluble material; ${ }^{\mathrm{d}}=$ gas percentage wt. $/$ wt.; ${ }^{\mathrm{e}}=$ inorganic material percentage wt./wt. 
of molybdenum affects the characteristics of liquid products resulting from degradation of the polymer. Addition of molybdenum on natural clay (NC) promoted the formation of products in kerosene to diesel range. Therefore, impregnation of metals was found to be effective in liquid yields and selectivity of products (Haag et al., 1981).

Effect of catalyst on gas yield was also studied and it was found that for LDPE, $12 \%$ charge of $\mathrm{NC}$ (without impregnation) gave $(36.13 \%)$ at $350{ }^{\circ} \mathrm{C}$, whereas, $5 \%$ load of nickel gave (19.27\%) and $10 \%$ load of molybdenum gave (26.63\% gaseous products). Similarly, for poly-bags $12 \%$ of neat NC catalyst gave (36.42\%), on the other hands $5 \%$ addition of nickel gave $(26.09 \%)$ and $10 \%$ molybdenum gave $(33.15 \%)$ gaseous products.

Catalytic performance of commercial catalyst on pyrolysis of LDPE and Poly-bags. Three commercial catalysts mordenite, USY zeolite, and AKZO KC-2710

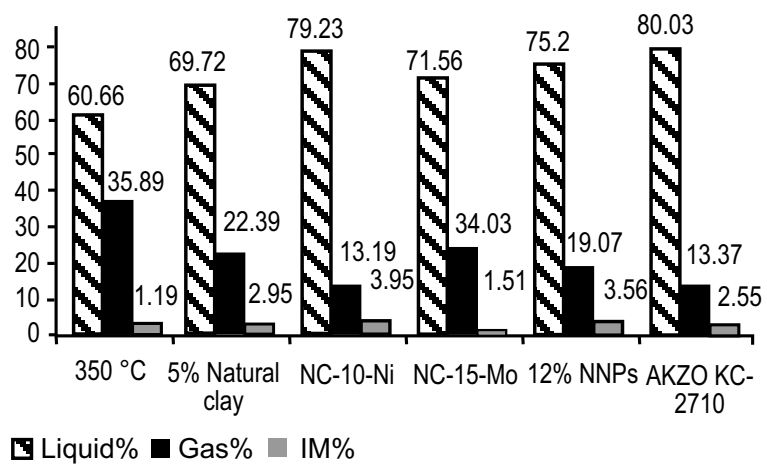

Fig. 3. Comparison of liquid, Gas and IM \% for LDPE at a maximum liquid product yield. were also studied for the comparison of performance of synthesized catalyst. Table 5 shows the outcome of these commercial catalyst at $5 \%$ load at $350{ }^{\circ} \mathrm{C}$. In general, commercial catalyst gave a higher amount of liquid products. Among them, catalyst AKZO KC-2710 from AkzoNobel found best for the production of liquid yield. It gave (80.00\%) liquid yield, IM material (2.55\%) and only (13.37\%) gas in case of LDPE.

These results are in full agreement with earlier work by (Abbas-Abadi et al., 2013; You et al., 2000). Catalyst AKZO KC-2710 gave the highest liquid product in case of poly bags. Figure 3 shows the comparison of liquid, gas and IM \% on LDPE at maximum liquid yield. Presence of catalyst shows a higher conversion compared with uncatalyzed reaction $(60.66 \%)$. Use of natural clay (NC) gave the maximum product yield with $10 \%$ impregnation of Nickel (79.23\%) compared with neat NC (69.72\%). Neat NC also gave $(22.39 \%)$ gas and small amount of inorganic material (IM) (2.95\%).

Addition of $12 \%$ of NNPs gave the liquid yield about (75.2\%). Similar, results with a marginal difference were obtained for used poly-bags as shown in Fig. 4.

Comparison of liquid products of LDPE and poly-bags with commercial gasoline, kerosene, and diesel are presented in Fig. 5a-b, respectively. Nickel nanoparticles (NNPs) gave the higher amount of high boiling point liquid, mainly in diesel range $(45.97 \%)$ and (36.71\%) for LDPE and used poly-bags, respectively. Natural clay (NC) impregnated with molybdenum gave the maximum product $(61.92 \%)$ for LDPE and $(59.61 \%)$ for poly-bags in the range of kerosene. Gasoline products are obtained in high yields with AKZO KC2710 commercial catalyst.

Table 5. Effect of commercial cracking on pyrolysis of LDPE and poly-bags

\begin{tabular}{|c|c|c|c|c|c|c|c|c|c|c|}
\hline \multirow[b]{2}{*}{ Polymer } & \multirow[b]{2}{*}{ Catalyst (\%) } & \multirow[b]{2}{*}{ Hex. $(\%)^{a}$} & \multirow[b]{2}{*}{ Tol. $(\%)^{b}$} & \multirow[b]{2}{*}{$\operatorname{THF}(\%)^{\mathrm{c}}$} & \multirow[b]{2}{*}{ Gas $(\%)^{d}$} & \multirow[b]{2}{*}{$\operatorname{IM}(\%)^{\mathrm{e}}$} & \multicolumn{4}{|c|}{ Normalized area of time (min.) } \\
\hline & & & & & & & Conversion & Start 0-20 & $20-40$ & $40-60$ \\
\hline \multirow[t]{3}{*}{ LDPE } & Mordenite & 73.00 & 2.07 & 2.06 & 21.33 & 2.58 & 98.42 & 41.52 & 45.61 & 12.87 \\
\hline & USY Zeolite & 75.50 & 1.43 & 3.99 & 17.23 & 4.87 & 98.13 & 34.12 & 40.14 & 25.74 \\
\hline & $\begin{array}{l}\mathrm{AKZO} \\
\mathrm{KC}-2710\end{array}$ & 80.00 & 2.47 & 1.58 & 13.37 & 2.55 & 97.45 & 48.64 & 43.76 & 7.60 \\
\hline \multirow[t]{3}{*}{ Poly bags } & Mordenite & 68.60 & 2.98 & 2.20 & 23.22 & 2.98 & 97.02 & 38.54 & 42.33 & 19.13 \\
\hline & USY Zeolite & 70.50 & 0.40 & 2.30 & 24.15 & 2.65 & 97.35 & 29.67 & 36.83 & 33.50 \\
\hline & $\begin{array}{l}\text { AKZO } \\
\text { KC-2710 }\end{array}$ & 73.10 & 1.20 & 3.77 & 17.59 & 4.38 & 95.62 & 47.56 & 42.69 & 9.75 \\
\hline
\end{tabular}

${ }^{\mathrm{a}} \mathrm{wt} .=$ percentage of hexane soluble material; ${ }^{\mathrm{b}} \mathrm{wt} .=$ percentage of toluene soluble material; ${ }^{\mathrm{c}} \mathrm{wt} .=$ percentage of THF soluble material; ${ }^{\mathrm{d}}$ gas percentage wt./wt.; ${ }^{\mathrm{e}}=$ inorganic material percentage wt./wt. 


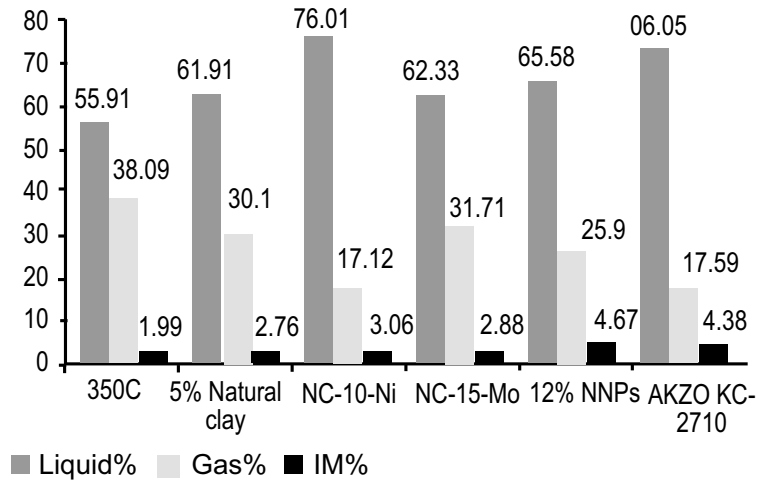

Fig. 4. Comparison of liquid, gas and IM \% for poly-bags at a maximum liquid yield.

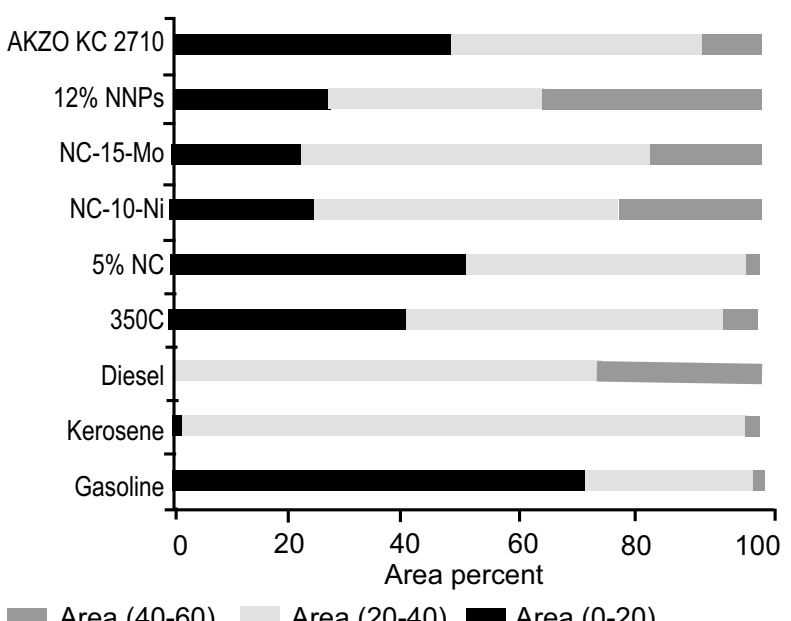

Fig. 5a. GC peak area comparison of liquid products distribution for LDPE.

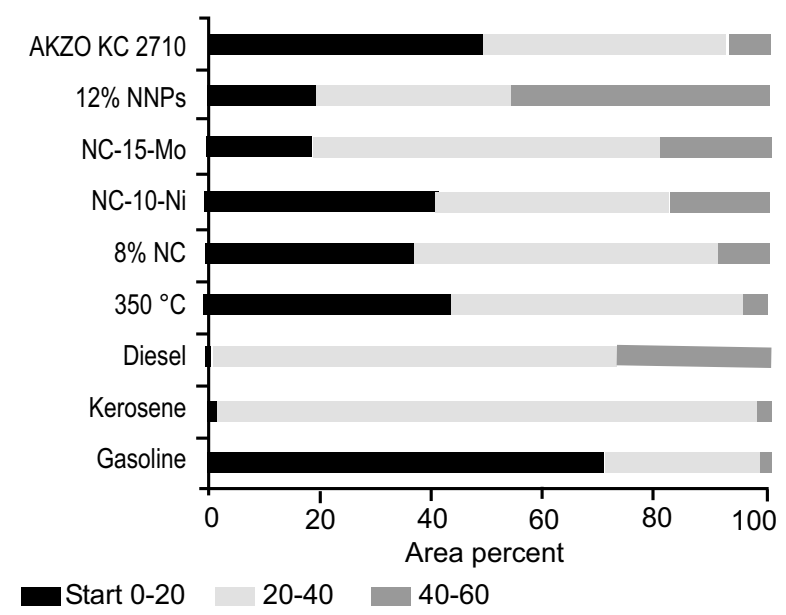

Fig. 5b. GC peak area comparison of liquid products distribution for poly-bags.

\section{Conclusions}

Important findings and cost. The primary purpose of this study is to develop cost-effective catalysis method using readily available materials such as natural clay impregnated with nickel nanoparticles. Such combinations have not been evaluated before. We demonstrated that the pyrolysis of waste polybags and pure LDPE could be conveniently converted to petroleum range fuels. Clay and nickel nanoparticles lower the pyrolysis temperature and increase the conversion of waste plastics into fuel. It also increases the yield of liquid fuel, which is highly desirable. The liquid fuel thus produced can satisfy the requirements of transportation fuels. Final products are of commercial values with product distribution in kerosene, gasoline and diesel range. Nickel impregnation $(10 \%)$ on natural clay gave the maximum liquid yield $79.23 \%$ and $76.01 \%$ for LDPE and polybags respectively.Nickel impregnation on natural clay enhances liquid quantity up to $12 \%$ for LDPE while $18.6 \%$ more liquid produced with poly-bags. Based on this study, we conclude that the option of converting waste plastic poly bags to liquid fuel is a good alternative method for obtaining new energy resources and eliminate the problems of plastics waste management. The proposed use of natural clay for recycling of waste plastic with new low-cost solutions opens a new area of research.

\section{Acknowledgment}

The authors would like to thank Prof. Dr. Farhat Ali and Dr. M. Farooq Wahab for helpful discussions, guidance, and support in this project.

Conflict of Interest. The authors declare no conflict of interest.

\section{References}

Abbas-Abadi, M.S., Haghighi, M.N., Yeganeh, H., McDonald, A.G. 2014. Evaluation of pyrolysis process parameters on polypropylene degradation products. Journal of Analytical and Applied Pyrolysis, 109: 272-277.

Abbas-Abadi, M.S., Haghighi, M.N., Yeganeh, H. 2013. Evaluation of pyrolysis product of virgin high density polyethylene degradation using different process parameters in a stirred reactor. Fuel Processing Technology, 109: 90-95.

Abbas-Abadi, M.S., Haghighi, M.N., Yeganeh, H. 2012 Evaluation of pyrolysis product of virgin high 
density polyethylene degradation using different process parameters in a stirred reactor. Fuel Processing Technology, 109: 90-95.

Abbas-Abadi, M.S., Haghighi, M.N., Yeganeh, H. 2012. The effect of temperature, catalyst, different carrier gases and stirrer on the produced transportation hydrocarbons of LLDPE degradation in a stirred reactor. Journal of Analytical and Applied Pyrolysis, 95: 198-204.

Ahmad, I., Khan, M.I., Ishaq, M., Khan, H., Gul, K., Ahmad, W. 2013. Catalytic efficiency of some novel nanostructured heterogeneous solid catalysts in pyrolysis of HDPE. Polymer Degradation and Stability, 98: 2512-2519.

Al-asadi, M., Miskolczi, N. 2018. Pyrolysis of polyethylene terephthalate containing real waste plastics using Ni loaded zeolite catalysts. Paper presented at the IOP Conference Series. Earth and Environmental Science, 154: 012-021.

Ali, M., Qureshi, M. 2013. Transportation fuels from catalytic co-pyrolysis of plastic wastes with petroleum residues: Evaluation of catalysts by thermo gravimetric analysis. Petroleum Science and Technology, 31: 1665-1673.

Ali, M.A., Asaoka, S. 2009. Ni-Mo-titania-alumina catalysts with usy zeolite for low pressure hydrodesulfurization and hydrocracking. Petroleum Science and Technology, 27: 984-997.

Ali, M.F., Ahmed, S., Qureshi, M.S. 2011. Catalytic co-processing of coal and petroleum residues with waste plastics to produce transportation fuels. Fuel Processing Technology, 92: 1109-1120.

Ali, S., Garforth, A., Fakhru'l-Razi, A. 2006. Recycling of polymer waste with fluid catalytic cracking catalysts Citation formats. Journal of Environmental Science and Health, Part A, 41: 1145-1154.

Das, P., Tiwari, P. 2018. Valorization of packaging plastic waste by slow pyrolysis. Resources, Conservation and Recycling, 128: 69-77.

Emam, E.A.2013. Clays as catalysts in petroleum refining industry. ARPN Journal of Science and Technology, 3: 356-375.

EPA, U. 1996. Microwave assisted acid digestion of siliceous and organically based matrices. USEPA, Method, 3052.

Haag, W.O., Lago, R.M., Weisz, P.B. 1981. Transport and reactivity of hydrocarbon molecules in a shapeselective zeolite. Faraday Discussion of the Chemical Society, 72: 317-30.

Hung-Ta, L., Mao-Suan, H., Jin-Wen, L., Li-Hsiang,
L., Chi-Ming, L., Keng-Liang, O. 2010. Hydrocarbon fuels produced by catalytic pyrolysis of hospital plastic wastes in a fluidizing cracking process. Fuel Processing Technology, 91: 13551363.

Johansson, A.-C., Sandström, L., Öhrman, O. G., Jilvero, H. 2018. Co-pyrolysis of woody biomass and plastic waste in both analytical and pilot scale. Journal of Analytical and Applied Pyrolysis, 134: 102-113.

Jung, S.H., Cho, M.H., Kang, B.S., Kim, J.S. 2010. Pyrolysis of a fraction of waste polypropylene and polyethylene for the recovery of BTX aromatics using a fluidizedbed reactor. Fuel Processing Technology, 91: 277-284.

Kahani, S., Molaei, H. 2013. Synthesis of nickel metal nano-particles via a chemical reduction of nickel ammine and alkylamine complexes by hydrazine. Journal of the Iranian Chemical Society, 10: 12631270.

Lerici, L.C., Renzini, M.S., Pierella, L.B. 2015. Chemical catalyzed recycling of polymers: catalytic conversion of PE, PP and PS into fuels and chemicals over HY. Procedia Materials Science, 8: 297-303.

Lin, X., Zhang, Z., Zhang, Z., Sun, J., Wang, Q., Pittman, C.U. 2018. Catalytic fast pyrolysis of a woodplastic composite with metal oxides as catalysts. Waste Management, 79: 38-47.

Marcilla, A., Gomez, A., Reyes-Labarta, J.A., Giner, A. 2003. Catalytic pyrolysis of pol-ypropylene using MCM-41: kinetic model. Polymer Degradation and Stability, 80: 233-240.

Marczewski, M., Kamiñska, E., Marczewska, H., Godek, M., Rokicki, G., Sokolowski, J. 2013. Catalytic decomposition of polystyrene. The role of acid and basic active centers. Applied Catalysis B: Environmental, 129: 236-246.

Moore, S.W. 1985. Solar absorber selective paint research. Solar Energy Materials, 12: 435-447.

Ozaki, M. 1989. Preparation and properties of welldefined magnetic particles. MRS Bulletin, 14: 3540.

Salvador, C., Cardona, A.C. 2000. Tertiary recycling of polypropylene by catalytic crackingin a semibatch stirred reactor use of spent equilibrium FCC commercial catalyst. Applied Catalysis B: Environment, 25: 151-162.

Sharuddin, S.D.A., Abnisa, F., Daud, W.M.A.W., Aroua, M. K. 2017. Energy recovery from pyrolysis of plastic waste: Study on non-recycled plastics (NRP) 
data as the real measure of plastic waste. Energy Conversion and Management, 148: 925-934.

Singh, M., Jharwal, M.K., Štìpánek, F., Ulbrich, P., Svoboda, P., Santava, E., Singla, M. 2011. Liquidphase synthesis of nickel nanoparticles stabilized by PVP and study of their structural and magnetic properties. Advanced Material Letters, 2: 409-414.

Singh, R.K., Biswajit, R. 2015. Plastic waste management and disposal techniques-Indian scenario. International Journal of Plastics Technology, 19: 211-226.

Su, H., Minn-Hwan, C., Bo-Sung, K., Joo-Sik, K. 2010. Pyrolysis of a fraction of waste poly-propylene and poly-ethylene for the recovery of BTX aromatics using a fluidizedbed reactor. Fuel Processing Technology, 91: 277-284.

Syamsiro, M., Saptoadi, H., Norsujianto, T., Noviasri, P., Cheng, S., Alimuddin, Z., Yoshikawa, K. 2014. Fuel oil production from municipal plastic wastes in sequential pyrolysis and catalytic reforming reactors. Energy Procedia, 47: 180-188.

Themelis, N.J., Mussche, C. 2014. Energy and economic value of municipal solid waste (MSW), including non-recycled plastics (NRP), currently landfilled in the fifty.

Vichaphund, S., Aht-ong, D., Sricharoenchaikul, V., Atong, D. 2017. Effect of CV-ZSM-5, Ni-ZSM-5 and FA-ZSM-5 catalysts for selective aromatic formation from pyrolytic vapours of rubber wastes. Journal of Analytical and Applied Pyrolysis, 124: 733-741.

Wagner, M., Schmidt, L. 1995. Model catalytic oxidation reactions: oxygen with $\mathrm{H}_{2}, \mathrm{NH}_{3}$, and $\mathrm{N}_{2} \mathrm{H}_{4}$ on $\mathrm{Rh}$ (111). The Journal of Physical Chemistry, 99:
805-815.

Wan Adibah, W.M., Cheng Tung, C., Chin Kui, C., Chern Lleing, L., Kristian, H., Peter Nai. Y., Nyuk Ling, M., Su Shiung, L. 2018. Production of valueadded liquid fuel via microwave co-pyrolysis of used frying oil and plastic waste. Energy, 162: 309-317.

Willams, P.T., Nazzal, J.M. 1995. Polycyclic aromatic compounds in shale oils: influence of process conditions. Environmental Technology, 19: 775-787.

Wilson, M.A., Burt, R., Lee, C.W. 2006. Improved elemental recoveries in soils with heating boric acid following microwave total digestion. Communications in Soil Science and Plant Analysis, 37: 513-524.

Y.-H. Lin., M.-H. Y. 2007. Chemical catalyzed recycling of waste polymers: catalytic conversion of polypropylene into fuels and chemicals over spent FCC catalystin a fluidized bed reactor. Polymer Degradition Stability, 92: 813-821.

You, Y.S., Seo, G. 2000. Liquid-phase catalytic degradation of polyethylene wax over MFI zeolites with different particle sizes. Polymer Degradation Stability, 70: 365-371.

Yu-Tung. Cheng, G. W. H. 2012. Production of targeted aromatics by using Diels-Alderclasses of reactions with furans and olefins over ZSM-5. Green Chemistry, 14: 3114-3125.

Zhou, G., Li, J., Yu, Y., Li, X., Wang, Y., Wang, W., Komarneni, S. 2014. Optimizing the distribution of aromatic products from catalytic fast pyrolysis of cellulose by ZSM-5 modification with boron and co-feeding of low-density poly-ethylene. Applied Catalysis A: General, 487: 45-53. 